\title{
Processos de integração na América Latina: convergência e/ou divergência
}

\author{
RUBENS RICUPERO
}

$\mathrm{H}$

á talvez duas maneiras de abordar o tema. A primeira seria um tanto vaga e retórica, quase de filosofia política. Subiríamos às alturas da generalização para afirmar com Teilhard Chardin a inevitabilidade da integração como sentido mais alto da história. Tout ce qui s'elève, converge [Tudo o que se eleva, converge]. Por ser geral e vaga a afirmação não é necessariamente falsa. Antes, penso que é verdadeira. Não nos ajuda muito, todavia, na busca dos caminhos praticáveis da integração.

A segunda maneira seria indagar se a integração regional, latino-americana ou outra, é compatível com a que está acima, a integração global do sistema mundial de comércio. Examinar, em seguida, quais são, aqui e agora, na América Latina, cinco anos antes do fim do século, as alternativas reais. Finalmente, tratar de identificar os obstáculos não só econômicos, mas também políticos que se apresentam diante de nós.

\section{Regionalismo e globalização}

Deixarei que me guie nesse tópico o excelente, sólido e matizado estudo analítico preparado pela Secretaria da Organização Mundial do Comércio e divulgado em abril sob o título de Regionalism and the world trading system.

Com a concisão que se impõe, resumirei algumas das principais constatações do relatório, na parte descritiva do fenômeno, para passar depois às suas conclusões, sem me deter a expor, por falta de tempo, os argumentos e as análises que levaram a esses resultados.

O trabalho da OMC parte das seguintes realidades:

\section{Descrição do fenômeno}

- Longe de ser moda recente, a integração regional é uma das características definidoras do período pós-Segunda Guerra Mundial - entre 1974 e 1994 foram notificados ao GATT, sob o artigo XXIV, 98 acordos, aos 
quais se deve acrescentar 11 mais, notificados por países em desenvolvimento sob a Cláusula de Habilitação de 1979 (a cifra real é superior, pois muitos acordos não foram especificados porque se supõe serem desdobramentos de um acordo quadro como, por exemplo, os numerosos acordos intralatino-americanos considerados parte da ALADI).

- A tendência acelerou-se em anos recentes - entre 1990 e 1994 foram notificados 33 acordos.

- O fenômeno é particularmente intenso na Europa Ocidental - dos 109 acordos notificados no período, os países europeus ocidentais são parte em 76; da mesma forma, os acordos concluídos após o derrocamento do muro de Berlim com as nações da Europa Central e Oriental respondem por 24 dos 33 acordos notificados nos últimos cinco anos.

- A integração européia é singular não só pela sua intensidade e crescente consolidação ao longo de quase 40 anos, mas também por seu caráter único - a motivação estratégico-ideológica inicial e as explícitas metas políticas e de defesa de Maastricht lhe conferem características absolutamente particulares, de exceção única, sendo arriscado deduzir da experiência européia lições de validade universal.

- A extensão da União Européia e a conclusão do Nafta significam que as relações comerciais e econômicas de dois dos maiores mercados do mundo são crescentemente condicionadas por acordos regionais, com implicações significativas para terceiros paises.

- Em $1^{\circ}$ de janeiro de 1995, momento fundador da OMC, quase todos os seus membros eram parte de pelo menos um acordo dos notificados ao GATT, com duas notáveis exceções: Japão e Hong Kong (até agora); a contrario sensu, todos os membros eram terceiras partes com relação a alguns acordos.

- São relativamente poucos os acordos notificados por países em desenvolvimento que tenham cumprido suas metas e seus prazos para estabelecer uma zona de livre comércio ou união aduaneira. As razões para isso seriam: a incompatibilidade entre integração e políticas econômicas dirigidas para dentro (a substituição de importações, por exemplo), o protecionismo setorial e autárquico, a instabilidade cambial, as oscilações políticas e econômicas, as dificuldades criadas pela crise internacional dos anos 80 .

- O nível de integração alcançado varia muito; a maioria das notificações refere-se apenas a áreas de livre comércio e ainda é pequeno o número de uniões aduaneiras (o relatório relaciona somente a Comunidade 
Européia, o Caricom e o Mercosul). A União Européia é a única união aduaneira membro de pleno direito da OMC, juntamente com seus Estados-membros.

\section{Conclusões do Relatório}

O relatório da Secretaria da OMC propõe-se a examinar "se os acordos de integração do após-guerra têm complementado ou debilitado os objetivos do sistema mundial de comércio" (igualmente pergunta-se se as normas e práticas do GARR/OMC são capazes de assegurar que as abordagens regional e multilateral se reforcem mutuamente, mas esse aspecto está fora do propósito de nossa análise).

Em razão da dificuldade de captar com precisão o impacto dos acordos de integração sobre o comércio e as relações comerciais, o estudo prefere comparar o crescimento do comércio dos participantes de ajustes entre si e com terceiros, antes e depois da conclusão desses acordos, e chega às seguintes conclusões:

- A análise não confirma a tese de uma crescente fragmentação regional do comércio nem a emergência de blocos mais ou menos exclusivos e excludentes na América do Norte, Europa Ocidental e região da ÁsiaPacífico; ao contrário, o comércio com parceiros dentro da mesma região e com parceiros de outras regiões tem sido crescentemente importante para as economias nacionais no período de após-gruerra.

- A Europa Ocidental é uma exceção à generalização anterior, por ser a única região que consistentemente perseguiu o aumento do comércio intra-regional por meio de políticas explícitas para tal fim. Entre $1958 \mathrm{e}$ 1993, a porcentagem do comércio intra-regional com relação ao total cresceu, na Europa Ocidental, de 53 a 70\%, com aumento mais intenso entre 1958 e $1973(67,7 \%)$.

- Mesmo na Europa Ocidental não houve mudanças significativas na importância do comércio extra-regional com relação à produção total da região. Esse comércio, que representava em 1958 cerca de 15,8\% do Produto Doméstico Bruto, havia baixado a 12,8\% em 1990 (notar que já era de 12,2\% em 1963 e 13,8\% em 1973). A explicação é que, entre 1958 e 1990, o comércio exterior aumentou de importância para a Europa Ocidental, passando de 33 a 45\% do PIB, deixando, assim, algum espaço para o comércio extra-regional.

- Registraram-se também aumentos, mas em menor escala, na participação do comércio intra-regional nos casos da América Latina (16,8\% em 1958 para 19,4\% em 1993) e Ásia (41,1 para 49,7\%). Em outras regiões, o comércio intra-regional manteve-se com poucas mudanças ou 
declinou; o relatório chama a atenção para o dramático exemplo de desregionalização ocorrido no comércio da Europa Central, Oriental e da ex-URSS, onde a participação intra-regional desabou de 61,3\% (1958) e de $71,3 \%$ (1963) para 19,7\% em 1993.

- As estimativas dos efeitos dos acordos regionais entre países desenvolvidos, especialmente na CEE, parecem demonstrar que a criação de comércio superou o efeito de desvio de comércio no caso dos manufaturados, sucedendo o oposto no caso da agricultura, não sendo claro se o balanço é positivo ou negativo.

- O efeito dinâmico de estímulo às importações provenientes de terceiros como resultado da aceleração do crescimento econômico acarretada pela integração explicaria porque são raras as reduções absolutas nas importações de terceiros, exceto em agricultura.

- O desvio de comércio tende a ser potencialmente mais importante em acordos entre países desenvolvidos que cobrem produtos nos quais subsistem picos tarifários (tecidos, confecções, calçados) e em agricultura; o mesmo ocorre em acordos entre países em desenvolvimento quando se outorga aos participantes margem de preferência relativamente elevada como sucedeu em muitos casos na América Latina.

- Os estudos empíricos indicariam que os acordos regionais tendem a produzir aumentos de investimentos originários de fora da região, desde que se encontrem presentes outros elementos econômicos que influem na decisão de investir. A experiência do programa do mercado único europeu em 1985 mostra que o impacto foi grande devido à eliminação ou redução de barreiras não-tarifárias e às restrições de acesso em setores de serviços, mais do que propriamente em razão de reduções tarifárias.

- Em alguns casos limitados, as partes de acordos regionais foram mais longe do que o GATT na eliminação ou redução de barreiras não-tarifárias (por exemplo, a renúncia a medidas anti-dumping no seio da Comunidade Européia e do acordo Austrália-Nova Zelândia) ou em certos casos de liberalização de serviços e propriedade intelectual (o Nafta, por exemplo).

- De maneira geral, pode-se dizer, porém, que as disciplinas da OMC cobrem terrenos mais amplos do que a maioria dos acordos regionais, tanto em serviços e propriedade intelectual, como em agricultura, medidas não-tarifárias (anti-dumping e anti-subsídios), na solução de controvérsias e em barreiras técnicas.

- Em conclusão, após lembrar que as "normas e procedimentos para as 
políticas relacionadas ao comércio" são a essência do sistema mundial de comércio, o relatório afirma que "as iniciativas de integração regional e multilateral têm sido complementárias mais que alternativas na busca de um comércio mais livre. Confirma, assim, a conclusão a que haviam chegado Robert Lawrence e Robert Littan, em estudo sobre The World trading system after the Uruguay Round, no sentido de que os grupos regionais se haviam comportado até agora mais como building blocks do que como stumbling blocks na construção de um sistema comercial aberto.

Se existe, pois, uma básica convergência dos processos regionais com a unificação de mercados em escala planetária a que se está assistindo no mundo contemporâneo, resta verificar se, no interior da América Latina, ou, de maneira mais ampla, no Hemisfério Ocidental, existiria a mesma convergência.

\section{Área hemisférica ou latino-americana?}

Se, em nível mundial, a decisão da Europa Ocidental de expandir a comunidade originária atuou como o fator catalisador do processo de integração e definidor dos termos do debate, esse papel foi desempenhado em nosso continente pela decisão do México de integrar-se ao Nafta e, mais tarde, pela iniciativa dos Estados Unidos de buscar uma Zona de Livre Comércio Hemisférica ou das Américas.

Em contraste com a Europa, onde o processo atual se desenvolve organicamente e sem fraturas desde o Tratado de Roma (com o abandono do que, em algum momento, se pensou pudessem constituir alternativas, a AELC e o Comecom), em nosso caso a estrada principal - os Tratados de Montevidéu 1960 ou 1980, a ALALC e a ALADI - é posta de lado em favor de atalhos que, de acordo com a expressão inglesa, tencionam short-cut o caminho para a integração.

A insatisfação com Montevidéu, primeira ou última versão, não é de agora, pois já em fins dos anos 60 o Grupo Andino entreteve o sonho ou ilusão de que, em menor número, se chegaria mais depressa à terra prometida.

Decisão muito mais radical foi a mexicana, em duplo sentido: primeiro, em buscar um acordo preferencial com países fora da ALADI; em segundo lugar, por haver preferido seguir a lógica da continuidade geográfica e da concentração do comércio em lugar da aspiração de integrar-se antes com parceiros do mesmo universo político-cultural, em níveis comparáveis de desenvolvimento mas com os quais são menos intensos o intercâmbio e a integração de infra-estrutura física.

Ao menos em aparência, tratou-se de uma opção preferencial pelos ricos, não apenas porque a riqueza os converte em melhores mercados ou fontes de 
investimentos e tecnologia inexistentes no Sul, mas, mais do que isso, houve algo mais profundo: a opção por um novo modelo de desenvolvimento, de economia, de integração ao mundo em processo de globalização. Quase se poderia dizer, a conversão a uma nova maneira de compreender a organização da produção em moldes mais liberais e que alguns autores chamam de convergência sistêmica.

Em complemento a esse impulso e demonstrando que ele the conferia melhores condições para reatualizar suas relações ao Sul, o México assinaria uma série de acordos com o Chile, a Colômbia, a Venezuela, a Bolívia, a América Central. $\mathrm{O}$ processo era autônomo e não significava meramente uma extensão do Nafta, apesar de alguns dos países que negociaram com o México terem acreditado que esses acordos lhes facilitariam, em seu devido tempo, a adesão ao acordo da América do Norte.

Uma situação ainda mais desafiadora é criada quando os Estados Unidos decidem propor uma Área de Livre Comércio Hemisférico, retomando o velho sonho de união comercial do Alasca à Patagônia esboçado pelo secretário de Estado Blaine, nos tempos do presidente Cleveland e dos albores do Panamericanismo.

Paralelamente a outras forças como as produzidas pela recuperação da estabilidade e do crescimento das economias latino-americanas, uma vez superada a crise dos anos 80 e a abertura e liberalização dessas economias, o Nafta, os acordos mexicanos de livre comércio e a proposta sobre a Área de Livre Comércio das Américas irão atuar poderosamente sobre o processo da ALADI e influir sobre outros processos em curso: o Mercosul, a reativação do Grupo Andino, o Acordo Venezuela-Colômbia.

Em que medida essas múltiplas iniciativas podem ser vistas como compatíveis e complementares? Até que ponto se excluem e se opõem, como se chegou a insinuar a respeito da proposta brasileira de uma Área de Livre Comércio da América do Sul? Ou, em outras palavras, onde estão as convergências e as divergências?

Partindo do mais concreto e mais próximo, é preciso reconhecer uma primeira divergência. No momento em que concedeu a países de fora da ALADI certo tipo de preferências como as consagradas no texto do Nafta, o México estaria obrigado pelo Artigo 44 do Tratado de Montevidéu (1980) a outorgar aos demais membros da ALADI as mesmas preferências, de acordo com os princípios de Nação Mais Favorecida e de Não-Discriminação. Como se sabe, após longas e difíceis tratativas, adotou-se o compromisso de um Protocolo Interpretativo do TM-80, pelo qual se concede a qualquer nação que haja assinado acordos preferenciais com países de fora da região a possibilidade de obter 
um waiver da aplicação do Artigo 44 por dez anos. Em compensação, impõe-se a obrigação de negociar, com os membros da ALADI que o solicitem, compensações comerciais pelas preferências outorgadas a países extra-regionais.

Em certa medida, a vigência, a partir de $1^{\circ}$ de janeiro de 1995, da Tarifa Externa Comum do Mercosul suscita também a necessidade de restabelecer as margens de preferência ou de oferecer alguma outra compensação. Em ambos os casos, o Mercosul comprometeu-se a renegociar, até fim de dezembro de 1995, com o México por um lado, com o Grupo Andino por outro, o patrimônio histórico da ALADI . No caso da negociação com o Grupo Andino tenta-se chegar igualmente a uma zona de livre comércio, possibilidade à qual o Mercosul acenou também na reunião de junho de 1995 em Assunção. Está, pois, em curso um processo para superar a primeira divergência tangível.

Ainda suponho que o problema se resolva dentro desse novo prazo, resta a questão mais relevante: como avançar em direção à zona de livre comércio, seja sul-americana, aladiana ou hemisférica?

A maior ou menor amplitude da meta do processo já traz consigo uma diferença inicial no desenho da configuração mesma desse processo. Existem, por exemplo, os que favorecem uma espécie de teoria de círculos concêntricos e de complexidade crescente. O primeiro círculo incluirá duas etapas. A primeira, mais ou menos concluída, refere-se à concretização da zona de livre comércio Venezuela-Colômbia e à entrada em vigor das tarifas externas comuns do Mercosul e do Grupo Andino, esta última parcialmente (há questões ainda não-solucionadas com o Peru, por exemplo). A segunda etapa, ora em curso, seria a negociação entre o Mercosul e o Grupo Andino, assim como com o Chile, a fim de chegar-se à constituição de uma Área de Livre Comércio da América do Sul. O princípio implícito nessa abordagem seria o de aproveitar, para facilitar a integração, as vantagens decorrentes da contiguidade de territórios e a complementariedade preexistente, tal como manifestada na existência prévia de certo grau de concentração de exportações e importações entre países limítrofes. O mesmo princípio, como se viu, foi invocado no caso da ALADI. As negociações não seriam simultâneas com as hemisféricas (haveria, portanto, uma prioridade sul-americana) e se concentrariam, em princípio, na busca de um acordo para liberalizar apenas o comércio de bens num primeiro momento (deixando, assim, para mais tarde questões como as de serviços, propriedade intelectual, investimentos etc.).

Outra opção seria a de negociações simultâneas entre os 11 países membros da ALADI, por meio da adoção de um cronograma específico e de um processo imperativo de aumento das margens de preferência. As negociações abarcariam não só tarifas e questões não-tarifárias mas também serviços, investimentos e compras governamentais. 
Existem argumentos igualmente convenientes em favor de cada uma dessas abordagens e não é difícil identificar no meio do debate que sobre elas se trava, na ALADI e outros foros, os interesses, temores e esperanças de diversos países. Não me envolverei nessa discussão por dois motivos. Não creio, em primeiro lugar, como acabo de dizer, que se trate aqui de um debate socrático com vistas à busca sincera e desinteressada da verdade. Em segundo lugar, penso que a discussão se revelará supérflua e, em fim de contas, a decisão será dada na prática por aqueles que sejam capazes de provar concretamente sua disposição de negociar compromissos de livre comércio no prazo de dez anos ou menos. Suspeito que a realidade será pouco linear e cartesiana e acabará por impor-se a necessidade de negociações mais ou menos simultâneas e sobre uma variedade de temas, entre eles a facilitação do comércio, serviços e compras governamentais.

Estou persuadido, em compensação, de não ser indiferente a alternativa que nos apresenta a negociação com os Estados Unidos e o Canadá. Aparece, por um lado, a hipótese de negociar segundo o sistema chamado de hub and spokes (eixo e raios), pelo qual Washington selecionaria os candidatos elegíveis, pouco mais do que um contrato de adesão ao Nafta, com base em condicionalidades prévias que tornariam em larga medida supérflua a negociação posterior. A fim de habilitar-se, o candidato teria de subscrever todo um corpus já definido de regras em serviços, propriedade intelectual, investimentos, competição, meio ambiente, padrões trabalhistas, aos quais pretendem alguns agregar comportamento político, qualidade de governação etc.

É interessante observar que são tão evidentes as desvantagens desse sistema que até o habitualmente prudente secretariado da OMC se desvia de sua circunspecção para condená-lo. Lembra o relatório que, em todos os sistemas desse tipo, os bens e serviços (e talvez também o capital e o trabalho) fluem mais livremente entre o eixo ( $h u b)$ e cada um dos raios (spokes) do que de um raio a outro.

Prossegue o estudo: "comparado à alternativa de uma união aduaneira ou de uma área de livre comércio englobando a todos os países vinculados por acordos de integração regional, o sistema hub and spokes será provavelmente menos liberalizador ou mais protecionista, por existir um risco de que o país-eixo - em geral o mais forte política e economicamente - modele os acordos com os paísesraios de maneira a tratar seletivamente das correntes de comércio sensípeis caso a caso - por exemplo, agricultura no caso de um raio, tecidos e confecções, no de um outro e assim por diante".

Além disso, o sistema provavelmente produzirá menores incrementos reais de renda para os países membros e será potencialmente menos criador de comércio para terceiros, tenderá a distorcer os padrões de investimento estrangeiro e a aumentar os custos administrativos. Era esse o sistema que, durante a primeira 
fase da Iniciativa Para as Américas, basicamente se propunha aos países candidatos, no fundo reduzidos, segundo essa concepção, a uma adesão pura e simples ao texto já aprovado do Nafta, negociado com o México em condições muito especiais.

Felizmente, pareceria que a Cúpula de Miami se teria inclinado em favor da opção mais realista e pragmática dos building blocks. Assim, exceto casos particulares como o Chile, os Estados Unidos reconheceriam a vantagem de negociar com grupos já consolidados, seja em nível sub-regional, como o Mercosul e o Grupo Andino, seja em nível de América do Sul, desde que alcance êxito a negociação entre os grupos sub-regionais para conformá-la. Além dos argumentos já avançados para preferi-la à opção hub and spokes, deve-se acrescentar que, unidos em grupos sub-regionais, os países latino-americanos aumentarão seu poder de barganha graças à superior escala de mercado e serão mais capazes de equilibrar, até certo ponto, um exercício fundamentalmente assimétrico.

\section{Dificuldades políticas e riscos econômicos}

Definir se preferimos buscar a integração em nível sub-regional ou sulamericano antes da grande aventura de integrar o Alasca à Patagônia é somente parte do problema, como também o é desenhar um mapa do caminho para se chegar a essa meta. Faltaria, ainda, identificar os obstáculos políticos que se erguem nesse caminho e verificar, quando chegarmos finalmente a Canaã, se haverá, como esperamos, leite e mel para todos.

Do ponto-de-vista da política externa dos países, não é pessimismo afirmar que a rota se apresenta agora mais incerta do que há um ano atrás. Desde então, a crise mexicana, a derrota de Clinton nas eleições de novembro de 1994, o controle do Congresso e de seus órgãos-chave por elementos de escassa afinidade com o projeto hemisférico, enfraqueceram o entusiasmo estadunidense pela idéia e toldaram de nuvens o horizonte.

O resultado negativo mais concreto foi que o Executivo teve de renunciar ao pedido de fast track para as negociações hemisféricas, até então acoplado à autorização negociadora da Rodada Uruguai e vítima das controvérsias para a aprovação desta última. Sem que o Executivo disponha de um mandato negociador, seria temerário aceitar negociações cujos eventuais resultados poderiam ser a posteriori modificados ou condicionados pelo Congresso. Os negociadores europeus e japoneses no GATT jamais aceitaram negociar com os Estados Unidos em tais bases, e melhor seria que os latino-americanos não confundissem documentos declaratórios, como os emanados de Miami, com um verdadeiro mandato negociador. É preciso considerar, ademais, que a reunião de Denver, etapa seguinte do processo lançado em Miami, está prevista para março de 1996, ano de eleições presumivelmente difíceis e decisivas nos Estados Unidos. 
Por outro lado, deve-se indagar realisticamente quais são as perspectivas de alcançar, por meio da integração hemisférica, os resultados comerciais e econômicos desejados pelos países latino-americanos e necessários para a solução dos seus problemas. Se, pela primeira vez, os Estados Unidos tornaram-se demandantes, e não demandados, nas relações econômicas com a América Latina, isso não se deve ao altruísmo nem à casualidade. Dependendo cada vez mais do comércio exterior, que passou de $17 \%$ do PIB nos anos 70 para, aproximadamente, $21 \%$ em 1990 (acrescentando os ganhos com os investimentos no exterior, esse conjunto em 1994 alcançou US\$ 1,8 trilhões ou 27\% do PIB), os norte-americanos convenceram-se, como disse o USTR Michey Kantor, de que a América Latina é "where the action is... where our future lies".

Uma das razões dessa afirmação é que as exportações dos EUA para a região aumentaram de US\$ 42 bilhões, em 1988, para US\$ 89 bilhões em 1994, incremento de 109\% (o México representava então 50\% desse aumento). Em comparação, as exportações latino-americanas para os Estados Unidos nesse mesmo período cresceram no ritmo mais reduzido de 74\%. Dados recentes da ALADI indicam que as importações latino-americanas de produtos originários dos EUA têm aumentado em países como Brasil e Argentina a taxas, em certos casos, cinco vezes superiores às do incremento de suas exportações ao mercado estadunidense. Como a propensão marginal a consumir produtos norte-americanos é, na América Latina, o dobro da asiática, os países latino-americanos serão responsáveis, até fins do século, por um volume de importações provenientes dos Estados Unidos maior do que as vendas americanas ao Japão e à Europa, desde que se mantenham as taxas de crescimento registradas até agora. Essa tendência, aliás, é confirmada pelo fato de que, a partir de 1992, os norte-americanos passaram a ter superávit na sua balança comercial com a América Latina, aumentando o excedente que tradicionalmente sempre acumularam no balanço de pagamentos (o qual incorpora serviços, juros, lucros etc.).

Não é minha intenção, ao alinhar tais dados, praticar uma espécie de terrorismo comercial, pois creio que o comércio deve ser uma rua de duas mãos. Não se pode, contudo, ignorar que fatos e tendências concretos e irrefutáveis como os acima mencionados nos apresentam um problema real.

Com efeito, no momento em que os países latino-americanos adotaram programas unilaterais de abertura comercial, principalmente devido à convicção de que essas reformas eram indispensáveis para combater a inflação e vir a ter economias mais eficientes, mas, em parte, também para atender a pressões dos EUA, do FMI e do Banco Mundial, tais países aceitaram, ao mesmo tempo, a possibilidade de registrar déficits crescentes na balança comercial. Isso ocorreu primeiro com o México, mais tarde com a Argentina e agora com o Brasil.

Num primeiro momento, o problema parecia manejável pois os déficits 
eram compensados sem dificuldades pelos fluxos financeiros atraídos pelas altas taxas de juros latino-americanos. O panorama muda, porém, radicalmente, em 1994, como resultado dos sete aumentos sucessivos da taxa de juros americana determinados pelo Federal Reserve, isto é, posteriormente, por efeito da recente crise mexicana. A partir de então, um novo tema aparece nos discursos do diretor-gerente do Fundo Monetário Internacional: a imprudência, o perigo para um país em depender da poupança externa por mais de dois ou três anos (talvez até menos) e a necessidade de reequilibrar rapidamente as contas comerciais e correntes.

Sem esperar pelo conselho, o México adota um ajuste recessivo e, em poucos meses, inverte sua situação de deficitária em superavitária com os Estados Unidos (en passant, não é demais recordar que se é injusto responsabilizar o Nafta pelo gigantesco déficit de tempos recentes, tampouco se pode negar que ele contribuiu fortemente para isso). É óbvio que o mercado aberto ou consolidado pelo Nafta irá, a partir de agora, ajudar o México a gerar exportações e completar seu ajuste. Mas num quadro como esse, persistindo para os Estados Unidos a necessidade de equilibrar sua balança comercial com o mundo, em ambiente de queda persistente do dólar, com a inversão da relação comercial mexicano-americana, antes favorável a Washington, será realista esperar que os demais latino-americanos encontrem os Estados Unidos dispostos a desempenhar com relação a eles o mesmo papel de salvador que vêm assumindo com o México? Haverá lugar suficiente no bote salva-vidas e, se não houver espaço para todos, a quem preferirão os americanos salvar?

Há aproximadamente três anos, ao falar em uma cerimônia no Kellog Institute of Management, em Evanston, Illinois, tive a ocasião de mencionar um estudo de Stephen Fidler, do Financial Times. Naquele momento ainda longe da crise mexicana, Fidler escrevia que a questão principal não era indagar se os países latino-americanos seriam ou não capazes de continuar a financiar os déficits de suas contas correntes, mas saber em que níveis de juros o fariam e, conseqüentemente, em que níveis de desenvolvimento compatível com esses juros. Desde de então, a crise mexicana deu uma atualidade dolorosa a essa observação.

Perguntava-me, naquele mesmo discurso, se o Congresso e os meios de negócios norte-americanos estariam conscientes de que, cedo ou tarde, os déficits latino-americanos teriam de desaparecer e que a contribuição para reequilibrar as contas comercias teriam de vir, em primeiro lugar, dos mercados dos Estados Unidos e do Canadá com relação ao México e a outros países que passem a fazer parte da área de livre comércio.

Sem nenhum maniqueísmo, recordei ao meu auditório que isso exigiria dos EUA a disposição de se abrir mais a exportações latino-americanas de produtos sensíveis (couros, tecidos, confecções, calçados, suco de laranja), setores nos 
quais, para mal de nossos pecados, se concentra o essencial do potencial de exportação brasileira. Exigiria também a determinação norte-americana de moderar, abrandar ou eliminar o uso de medidas como as anti-dumping contra exportações latino-americanas. É sabido que um dos motivos que levaram o México a buscar um acordo de livre comércio com os Estados Unidos foi justamente a esperança de um tratamento especial nesse domínio, o que parece tardar a se concretizar a julgar pela ação impiedosa do Departamento de Comércio contra o cimento mexicano, por exemplo, para citar apenas um dentre muitos casos.

Com efeito, o dilema central da integração com a América do Norte reside nessa questão: se, de um lado, os latino-americanos não devem depender de recursos financeiros externos para compensar déficit comerciais, a não ser por períodos breves (conforme recomenda o próprio FMI) e se, de outro, não se pode razoavelmente supor que esses países encontrem as oportunidades para reequilibrar seu comércio em mercados terceiros da Europa e do Japão, fora da zona preferencial, onde irão eles buscar os compradores de que necessitam? É óbvio que será dentro da área hemisférica preferencial e, portanto, sobretudo nos Estados Unidos. Mas como fazê-lo se o mercado norte-americano não renunciar a aplicar de forma arbitrária, como vem fazendo, o arsenal anti-dumping e anti-subsídios e se esse mesmo mercado não aceitar negociar produtos sensíveis de setores domésticos crepusculares (têxteis, calçados, couros, suco de laranja), aos quais se agregam, no caso do Brasil, os produtos siderúrgicos? Aos que apontarem para o recente êxito mexicano como prova de que é possível, lembre-se que o México só está revertendo a corrente comercial com os EUA após forte desvalorização e um ajuste severamente recessivo que fez retroceder em dez pontos o PIB no segundo trimestre de 1995, reprimindo o consumo e as importações e liberando produtos para exportar. Tem de haver um método melhor.

Para isso, seria indispensável que, na etapa preparatória da reunião de Denver, nós, latino-americanos, saibamos redescobrir a capacidade de concertação que outrora tivemos, numa época em que a ânsia de merecer figurar na lista de bom comportamento de Washington não nos fazia esquecer a necessidade de tratar de definir nossa própria agenda de negociação, por meio de organismos como a antiga CECla (Comissão Econômica de Coordenação Latino-Americana) ou o SELA de hoje (Sistema Econômico Latino Americano).

$\mathrm{Na}$ ausência de tal coordenação, o que hoje vemos é uma tendência ao domínio da agenda por parte de norte-americanos e canadenses, que dão às vezes a impressão de querer transformá-la na agenda de negociações de todo o unfinished business da Rodada Uruguai, com prioridade para temas como serviços financeiros ou a opção de tarifa zero para produtos químicos. Isso não deverá surpreender nem indignar a ninguém, se se considera que as negociações comerciais sempre foram impulsionadas ou freadas nos Estados Unidos pelos 
interesses de setores econômicos organizados, como foi o caso, na Rodada Uruguai, da centralidade da questão da propriedade intelectual por obra basicamente de um único setor, o farmacêutico, organizado na Pharmacentical Manufacturers Association. A fim de bem compreender a motivação norte-americana, seria necessário lembrar constantemente a frase famosa de um presidente que quase não falava e, por isso, media muito as palavras, Calvin Coolidge: The business of the United States is business.

Assim, pois, deveríamos insistir, do nosso lado, por uma agenda que contenha o unfinished business não somente da Rodada Uruguai, mas também da Rodada Tóquio, uma vez que os resultados foram extremamente modestos em áreas como a liberalização da agricultura, têxteis, melhor disciplina para as medidas anti-dumping e compensatórias de subsídios. Muito pouco se fez para resolver o que ficou sobrando de Tóquio: os picos aduaneiros sobre produtos sensíveis (como as altíssimas tarifas específicas norte-americanas sobre suco de laranja), o escalonamento tarifário conforme se sobe no grau de elaboração de um produto, os produtos tropicais etc.

Seria igualmente necessário resistir à tendência que vem ganhando terreno nos Estados Unidos para considerar o Nafta não como um teto, mas como o piso de uma negociação na qual se exigiria de cada novo candidato pagar um bilhete mais caro para ingressar.

Na suposição de que tudo isso se realize e que saibamos negociar com algum equilíbrio, deve-se sublinhar que o êxito ou fracasso final do processo de integração hemisférica depende de fatores que transcendem o alcance da negociação comercial e requerem decisões em outras áreas. Refiro-me a dois aspectos centrais presentes na explicação do sucesso do modelo dos países asiáticos, os quais, diga-se de passagem, não tiveram necessidade, até agora, de qualquer esquema preferencial entre eles ou com países desenvolvidos para chegar onde chegaram.

O primeiro desses fatores é uma adequada taxa de poupança doméstica, ausente em nosso caso, exceto no caso do Chile, e que é, por sua vez, o produto de uma saudável situação macroeconômica: estabilidade em termos de uma longa tradição de inflação baixa, equilíbrio orçamentário, política realista de taxas de câmbio que soube evitar o uso dessas taxas para fins anti-inflacionários por tempo excessivo, com a conseqüência de destruir gradualmente a capacidade de exportar.

O segundo fator é justamente a demonstrada capacidade dos asiáticos de modificar estruturalmente a composição das exportações com o aumento gradual e sensível da porcentagem de manufaturados de alto grau de valor agregado como os produtos eletrônicos e óticos, setores que apresentam um crescimento de, às vezes, mais do que o dobro da taxa de expansão do comércio de manufaturados em geral. 
Em contraste com essa situação, estamos cada vez mais dependentes da concentração do essencial de nosso potencial exportador em domínios nos quais as vantagens comparativas provêm, ou da abundância de recursos naturais, ou da escala de produção. Muitos desses setores estão entre os mais vulneráveis a modalidades novas de protecionismo particularmente insidiosas, como são as do protecionismo ambiental (caso, por exemplo, das exportações de papel, celulose, produtos de pesca, aço, ferro, minérios, alumínio, produtos vegetais ou animais vulneráveis a barreiras sanitárias etc.).

A verdade é que, tanto no caso dos fatores macroeconômicos, como nos que dizem diretamente respeito à competitividade, a solução não nos virá de alguma mão invisível do mercado, mas necessitará políticas mais globais, metacomerciais e que incluam até mesmo o tema das reformas social, educacional e cultural. Não se deveria, assim, cometer o erro de oversell a integração, seja latino-americana, seja hemisférica, atribuindo-lhe vagamente poderes mágicos de transformação que, por si só, ela não pode ter.

Outra ameaça potencialmente grave que temos de vencer é o escasso progresso registrado na integração política e de segurança coletiva, apesar da abundância de encontros de cúpula e do abuso da retórica. Na Europa Ocidental, a integração econômica foi o resultado de uma decisão política de evitar a repetição de um novo conflito mundial e a fim de melhor fazer frente à ameaça de Stalin e do Exército Vermelho.

Lembrava Karl Deutsch, em seu estudo sobre a integração no Atlântico Norte, que existiam dois tipos de integração política. Chama o primeiro de $c^{-}$munidade de segurança amalgamada, na qual unidades antes autônomas delegam parte do seu poder soberano a um centro novo. É o caso, por exemplo, das 13 colônias que constituíram os Estados Unidos da América e poderia vir a ser, eventualmente, o caso dos sonhados Estados Unidos da Europa, até hoje apenas um mito criador, como disse um escritor francês.

Já o segundo tipo, a comunidade de segurança não-amalgamada, é aquela na qual, mesmo conservando o essencial da soberania e da autonomia, as unidades estatais alcançam um grau intenso de interação nos mais variados domínios e passam a recorrer a métodos institucionalizados para resolver pacificamente suas divergências ao longo de período suficientemente prolongado para tornar a hipótese de guerra entre elas improvável ou implausível. Seria esse o caso, por exemplo, das relações hoje em dia entre a França e a Alemanha, a Bélgica e a Holanda, os Estados Unidos e o Canadá os quais, pelo tratado de Washington da década de 1870, decidiram desmantelar todas as fortificações militares ao longo de sua fronteira.

Em nossa América do Sul, recentemente abalada por uma guerra, ainda 
que limitada entre o Peru e o Equador, na qual Chile e Argentina quase se entrechocaram por causa do Canal de Beagle não muito tempo atrás, em que subsistem litígios como Bolívia-Chile, Colômbia-Venezuela, Venezuela-Guiana, Guiana-Suriname, que país ou países poderiam pensar em algo parecido? Estamos infelizmente muito distantes de um mínimo razoável de integração política e do ideal da comunidade de segurança não-amalgamada, não obstante toda a retórica bolivariana.

A integração não é um jogo de soma zero. Deve ser predominantemente vista e percebida como uma oportunidade. Constitui um elo de um processo mais amplo que é a tendência deste fim de século para a unificação dos mercados em escala planetária. A meta final tem de ser sempre o multilateralismo, o sistema mundial e integrado de comércio que maximize os ganhos em todos os teatros de jogo, e não a perspectiva sub-regional ou regional.

Nesse sentido, estamos apenas no começo do princípio de um longo processo em que, a fim de nos guardarmos das frustrações passadas, devemos convergir com a vontade política de não tentar compensar, através da falta de generosidade com os vizinhos, os nossos próprios erros e insuficiências internos.

Rubens Ricupero, diplomata, é secretário-geral da Unctad (Conferência das Nações Unidas sobre Comércio e Desenvolvimento)e integrante da área de Assuntos Interna-cionais do Instituto de Estudos Avançados da UsP.

Palestra feita pelo autor no Seminário $A$ cooperação andina de fomento e a integração hemisférica, realizado em 6 de junho de 1995, em Caracas, Venezuela. 